\section{Commentary: Signet ring cell: One bad apple spoils the bunch!}

\author{
Andrew Tang, MD, MS, and Siva Raja, MD, PhD
}

The presence of signet ring features in esophageal adenocarcinoma has always been a harbinger of a worse prognosis in a disease with an often bad prognosis. Corsini and colleagues provide us unique insight into signet ring cell adenocarcinomas based on their vast esophageal cancer database. Through diligent review of historic pathology slides spanning across 2 decades, they demonstrate in this issue of the Journal that even small percentages of signet ring cell histology portend a worse prognosis in esophageal cancer survival. ${ }^{1}$

The World Health Organization has specified that signet ring cell adenocarcinomas only qualify as such when they contain $>50 \%$ signet ring features. Several studies have demonstrated that patients with signet ring cell histology have worse response to chemoradiation, greater likelihood of positive surgical margins, and ultimately worse survival. ${ }^{2-6}$ However, this is the first study to evaluate survival by breaking down the percentage of signet ring cell histology. Although the tumors with signet ring features had worse complete tumor response, the authors did not find that the degree of signet ring percentage correlated with the degree of tumor response. Similarly, greater percentages of signet ring cell histology did not translate into worse survival compared with lower percentages of signet ring features. Based on conventional wisdom one would have expected to see a difference. This finding could be related to the overall small study cohort, as it may be underpowered to detect survival differences between the varying degrees of signet ring features. Alternatively, this finding could be due to sampling error, as the percentage of signet ring cells was based on

\footnotetext{
From the Department of Thoracic and Cardiovascular Surgery, Cleveland Clinic, Cleveland, Ohio.

Disclosures: The authors reported no conflicts of interest.

The Journal policy requires editors and reviewers to disclose conflicts of interest and to decline handling or reviewing manuscripts for which they may have a conflict of interest. The editors and reviewers of this article have no conflicts of interest.

Received for publication Sept 7, 2020; revisions received Sept 7, 2020; accepted for publication Sept 9, 2020; available ahead of print Sept 14, 2020.

Address for reprints: Siva Raja, MD, PhD, Department of Thoracic and Cardiovascular Surgery, Cleveland Clinic, 9500 Euclid Ave/Desk J4-133, Cleveland, OH 44195 (E-mail: rajas@ccf.org).

J Thorac Cardiovasc Surg 2021;162:1413-4

$0022-5223 / \$ 36.00$

Copyright (c) 2020 by The American Association for Thoracic Surgery

https://doi.org/10.1016/j.jtcvs.2020.09.036
}

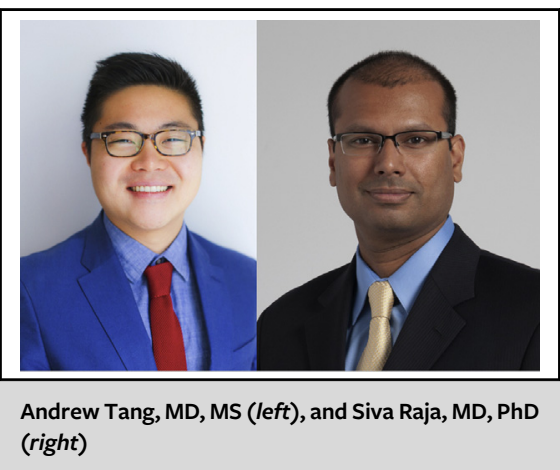

\section{CENTRAL MESSAGE \\ Any degree of signet ring fea- tures on pretreatment biopsy portends worse prognosis, mak- ing it the proverbial bad apple that spoils the bunch.}

endoscopic biopsies. The authors of this study were unable to assess the post-treatment specimens for the percentage of signet ring morphology, as many of them had lost their signet ring features. This is a new phenomenon indeed, as it has not been our experience to see regression of signet ring cells with a complete response. While the jury may still be out on the correlation between percentage of cells with signet ring features and prognosis, there no doubt from this study, and others, that it has a worse prognosis. $^{2}$

Given the worse prognosis of any amount of signet ring features, this study makes the case to use this threshold rather than the $>50 \%$ rule. Maybe we should treat the signet ring cell as the proverbial rotten apple that spoils the bunch.

\section{References}

1. Corsini EM, Foo WC, Mitchell KG, Zhou N, Maru DM, Ajani JA, et al. Esophageal adenocarcinoma with any component of signet ring cells portends poor prognosis and response to neoadjuvant therapy. J Thorac Cardiovasc Surg. 2021;162: 1404-12.e2.

2. Chen L, Liu X, Gao L, Wang R, Gao D, Bai D. The clinicopathological features and prognosis of signet ring cell carcinoma of the esophagus: a 10-year retrospective study in China. PLoS One. 2017;12:1-11.

3. Chirieac LR, Swisher SG, Correa AM, Ajani JA, Komaki RR, Rashid A, et al. Signet-ring cell or mucinous histology after preoperative chemoradiation and survival in patients with esophageal or esophagogastric junction adenocarcinoma. Clin Cancer Res. 2005;11:2229-36.

4. Tang A, Rappaport J, Raja S, Bribriesco AC, Sudarshan M, Siddiqui HU, et al. Signet ring cell histology confers worse overall survival in treated esophageal adenocarcinoma. Ann Thorac Surg. June 31, 2020 [Epub ahead of print]. 
5. Patel VR, Hofstetter WL, Correa AM, Agarwal A, Rashid A, Bhutani MS, et al. Signet ring cells in esophageal adenocarcinoma predict poor response to preoperative chemoradiation. Ann Thorac Surg. 2014;98:1064-71.
6. Wan Z, Huang Z, Chen L. Survival predictors associated with signet ring cell carcinoma of the esophagus (SRCCE): a population-based retrospective cohort study. PLoS One. 2017;12:e181845.
See Article page 1404.

\section{Commentary: Lowering the threshold rings in a new harbinger}

\author{
Dustin K. Lieu, BS, and Anthony W. Kim, MD
}

Signet ring cell (SRC) esophageal adenocarcinomas represent a subset of malignancy that exhibit particularly aggressive behavior and are associated with poor prognoses relative to non-SRC esophageal adenocarcinomas. ${ }^{1}$ In their study, Corsini and colleagues ${ }^{2}$ challenge the existing binary definition of SRC esophageal adenocarcinoma by providing evidence to support that tumors with any number of SRCs, including those with $\leq 50 \%$, portend the same poor prognosis associated with classically termed SRC esophageal adenocarcinomas with $>50 \%$ SRCs.

Performing a retrospective analysis, the authors identified 819 patients who underwent esophagectomy following neoadjuvant chemoradiation therapy for esophageal adenocarcinoma over a 12-year period at their institution. Of these patients, 106 were noted to have varying degrees of SRCs on pretreatment biopsy. Tumors were characterized further according to the percentage of SRCs based on a review of available specimens by an esophageal pathologist and were recategorized into 3 groups based on pretreatment SRC proportions. On multivariable analysis, the authors found that the presence of SRCs in any amount was an independent predictor of worse overall survival. Interestingly, however, there was no statistically significant relationship between the percentage of pretreatment SRC and overall

Division of Thoracic Surgery, Keck School of Medicine, University of Southern California, Los Angeles, Calif.

Disclosures: The authors reported no conflicts of interest.

The Journal policy requires editors and reviewers to disclose conflicts of interest and to decline handling or reviewing manuscripts for which they may have a conflict of interest. The editors and reviewers of this article have no conflicts of interest.

Received for publication Sept 7, 2020; revisions received Sept 7, 2020; accepted for publication Sept 10, 2020; available ahead of print Sept 14, 2020.

Address for reprints: Anthony W. Kim, MD, Division of Thoracic Surgery, Keck School of Medicine, University of Southern California, 1510 San Pablo St, Los Angeles, CA 90033 (E-mail: anthony.kim@med.usc.edu).

J Thorac Cardiovasc Surg 2021;162:1414-5 $0022-5223 / \$ 36.00$

Copyright $(9) 2020$ Published by Elsevier Inc. on behalf of The American Association for Thoracic Surgery

https://doi.org/10.1016/j.jtcvs.2020.09.037

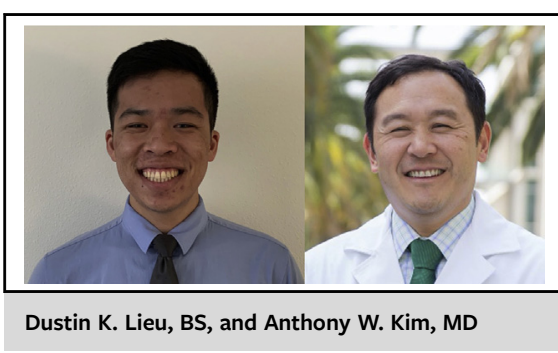

CENTRAL MESSAGE

The $>50 \%$ threshold defining signet ring cell (SRC) esophageal adenocarcinoma deserves a reexamination and discussion, as the mere presence of any SRCS may actually be clinically significant.

survival within the 3 SRC patient subcategorizations. Similarly, tumors with any proportion of SRC cells were noted to have lower pathologic complete response rates compared with non-SRC esophageal adenocarcinomas, with no significant trend associated with tumor regression grade among the 3 SRC cohorts.

The authors indicate that their study was limited by a sample size that may have been underpowered to detect differences within the spectrum of SRC esophageal adenocarcinomas. While possibly true and valid, it also is possible that even with greater numbers the lack of differences would still persist, owing to the ostensibly binary outcome associated with the simple presence of SRCs as their study implies. Alternative formats or clinical trials to evaluate the issue of whether the mere presence of SRCs is a determinant of survival could reduce variability in tumor sampling and assessment. ${ }^{3}$ However, at the expense of putting forth a circular argument, the utility of controlling for these issues may be unnecessary if, quite simply, the identification of any SRCs is found to have a prognostic value equal to that of a greater threshold percentage of SRCs such as $50 \%$. Furthermore, the current threshold for defining 